\title{
Randomised controlled trial of an intervention to improve parental knowledge and management practices of fever
}

M. Kelly ${ }^{1,2}$, L. Sahm ${ }^{1,3}$, S. McCarthy ${ }^{1,4}$, R. O'Sullivan ${ }^{5,6}$, A. Mc Gillicuddy and F. Shiely ${ }^{2,7^{*}}$ (D)

\begin{abstract}
Background: We know that parents require resources which can assist them to improve fever knowledge and management practices. The purpose of this study, using an RCT, was to examine the effectiveness of an information leaflet at increasing parental knowledge of fever, specifically temperature definition.

Methods: A prospective, multi-centre, randomised, two-parallel arm, controlled trial with blinded outcome ascertainment was conducted. Parents presenting at purposively selected healthcare facilities who had a child aged $\leq 5$ years of age were invited to participate. An information leaflet for use in the trial was designed based on previous studies with parents. Parents in the intervention arm read an information leaflet on fever and management of fever in children, completed a short questionnaire at Time 1 (T1) and again 2 weeks after randomisation at Time 2 (T2). Parents in the control arm did not receive the fever information leaflet but completed the same questionnaire as the intervention arm at $\mathrm{T} 1$ and againat $\mathrm{T} 2$. The primary outcome was the correct definition of fever (higher than $\geq 38^{\circ} \mathrm{C}$ ).

Results: A total of 100 parents participated in the study at T1. A greater proportion of the intervention group (76\%) than the control group (28\%) selected the correct temperature $\left(\geq 38^{\circ} \mathrm{C}\right)$ at $T 1.76 \%$ of the intervention arm correctly identified "higher than $\geq 38^{\circ} \mathrm{C}$ " as the temperature at which a fever is said to be present compared to $28 \%$ of the control arm. After 2 weeks, there was an increase of $6 \%$ of parents in the intervention arm (increase to 82.4\%) who gave the correct temperature compared to just a $2.8 \%$ increase in the control arm (increase to 30.8\%). Univariate logistic regression showed that parents in the intervention arm were significantly more likely to give the correct answer at both time-points (T1: OR 8.1; Cl 95\% 3.3-19.9: $p<0.01$; T2: OR 10.5; Cl 95\% 3.4-32.0: $p<0.01$ ).
\end{abstract}

Conclusions: Our RCT of this simple educational intervention has been shown to improve parental understanding of fever knowledge and correct management strategies. Education interventions providing simple, clear information is a key step to decreasing parental mismanagement of fever and febrile illness in children.

Trial registration: ClinicalTrials.gov NCT02903342, September 16, 2016, Retrospectively registered.

Keywords: Fever, Knowledge, Parent, Randomised controlled trial, Information leaflet

\footnotetext{
* Correspondence: f.shiely@ucc.ie

${ }^{2}$ Trials Research and Methodologies Group (TRAMS), HRB Clinical Research

Facility, Mercy University Hospital, Cork, Ireland

${ }^{7}$ School of Public Health, University College Cork, Cork, Ireland

Full list of author information is available at the end of the article
}

(c) The Author(s). 2019 Open Access This article is distributed under the terms of the Creative Commons Attribution 4.0 International License (http://creativecommons.org/licenses/by/4.0/) which permits unrestricted use, distribution, and reproduction in any medium, provided you give appropriate credit to the original author(s) and the source, provide a link to the Creative Commons license, and indicate if changes were made. The Creative Commons Public Domain Dedication waiver (http://creativecommons.org/publicdomain/zero/1.0/) applies to the data made available in this article, unless otherwise stated. 


\section{Background}

We know that parents require resources which can assist them to improve fever knowledge and management practices, and this is supported in the literature [1-6]. Fever is one of the most common childhood symptoms $[3,5,7-11]$ and is defined as a temperature of greater than $38^{\circ} \mathrm{C}[12,13]$. Fever is usually a self-limiting symptom with very low rates of associated serious illness [14-17].

Despite the benign nature of fever, parents often become alarmed and very concerned [4, 18-27]. Previous literature has demonstrated that this often leads to; aggressive treatment strategies; unnecessary and incorrect use of antipyretics [28-34]; and parents seeking medical advice [13, 19, 32, 35-38]. Consequently, fever is one of the most common reasons for consultations with healthcare professionals (HCPs) [5, 7, 39-45]. Many of these consultation could be avoided if there was clarity on fever definition and fever management practices.

The management of fever by antipyretics is acceptable, when there is associated signs of distress [8]. In medical practice alternating antipyretics is deemed necessary when fever occurs with other symptoms (e.g. otitis media, pain), however, guidelines suggest that antipyretics should not be alternated to manage fever in the absence of distress [8, 46-48]. The inherent problem with alternating antipyretics is that sometimes, a concerned parent may become confused as to what antipyretic they last administered and this may lead to dosing errors. Dosing regimens with antipyretics can lead to confusion as although similar, maximum numbers of administrations per day differ. For example, in Ireland, for a child aged 7-9 years, Calpol (Paracetamol) is administered up to 4 times per day while Neurofen (Ibuprofen) is administered up to three times per day. This can lead to possible safety issues when alternating antipyretics. HCPs, especially general practitioners (GPs) are giving appropriate information when they suggest alternating in specific cases (e.g. fever accompanied with distress despite monotherapy) $[8,49]$. However, our previous research has shown that parents alternate between antipyretics both with and without the presence of distress [6]. Manufacturers have attempted to address the dangers associated with overdosing children with antipyretics by adjusting dosing schedules to include narrower age bands and including doses calculated based on weight. This serves to underpin the problems with unintentional overdose with antipyretics. However, this does not address the use of antipyretics when there is no need. The purpose of our study was thus to address this need. Our prior research has shown that parents have requested accessible, consistent and reliable information resources to be made available to them $[1,2,6,50]$, with a particular desire for paper-based information resources $[1,6]$. We know that educational interventions increase parental knowledge and decrease clinic visits and consultations for fever and other minor illnesses [51-59]. thus potentially easing the burden on HCPs and providing a cost saving for the health service as well as the family seeking medical help [60].

\section{Aim of study}

The primary aim of this study was to examine the effectiveness of an information leaflet at increasing parental knowledge of fever, specifically temperature definition. Secondary outcomes were improvements in understanding of preferred management practices for antipyretic use and tepid sponging and knowledge retention after 2 weeks.

\section{Methods}

Study design

A prospective, multi-centre, randomised, two-parallel arm, controlled trial with blinded outcome ascertainment.

\section{Study sample}

Parents presenting at purposively selected GP practices, urgent and emergency care treatment centres and pharmacies in Cork, Ireland were invited to participate. The locations were selected to maximise population variation. A total of two GP practices, two urgent and emergency care surgeries and two community pharmacies participated. Any person attending these locations who had at least one child aged $\leq 5$ years of age was invited to participate. Potential participants were approached by MK only, a research pharmacist, not involved in their care. Utilising one researcher for data collection reduces the chances of observer bias. They were asked if they had a child aged $\leq 5$ years of age. If participants indicated that they had a child of this age, the study was explained in detail to them, they were given an information leaflet about the study and written informed consent was obtained. Each participant was given a study number, which were consecutively assigned. Following this process, MK opened the envelope corresponding to the participant's study number and parents were randomised to either the control or intervention arm of the study. All participants who consented to this study were parents and will be referred to as parents throughout.

\section{Information leaflet design}

An information leaflet (Additional file 1: Appendix 1) for use in the trial was designed based upon our two previous studies with parents $[1,6]$. Previous research included conducting a large scale quantitative study with parents using a questionnaire to gather data [6]. The questionnaire was developed and used in previous research [13]. We modified the questionnaire to reflect custom and practice in Ireland and piloted with a sample 
of five parents. It consisted of 38 questions with subthemes (Additional file 1: Appendix 2). The questionnaire assessed parental knowledge, help-seeking behaviours and expectations, needs for additional resources, fever management practices, use of pharmaceutical products, and concerns, attitudes and beliefs.

To develop the leaflet we sought input from five stakeholders including parents, pharmacists, doctors and nurses was also sought before the final leaflet was designed. The National Adult Literacy Agency (NALA) reviewed and revised the leaflet to ensure the language used was presented in a non-technical manner and was easily understood [61]. The leaflet meets plain English standards and carries the Plain English Mark [61]. Parents did not receive any reward for participation.

\section{Intervention arm}

Parents in the intervention arm of the study were given the information leaflet. After reading the leaflet, they then completed an initial questionnaire The questionnaire consisted of twenty questions - demographics, questions on knowledge of fever and antipyretic use, and measures of satisfaction with the fever information leaflet (See Additional file 1: Appendix 3). Parents were asked to provide contact details and a preferred contact time to participate in a similar follow up questionnaire (Additional file 1: Appendix 4) 2 weeks after randomisation. Parents were contacted by telephone 2 weeks later, at which time the follow-up questionnaire was completed. Parents were not given a specific date or time to ensure true learning effects from the leaflet were observed. At randomisation, if parents indicated that they would prefer to do the questionnaire at home and return by post, they were provided with stamped addressed envelopes to do so. All parents were contacted a maximum number of three times. If after three attempts to contact them, no contact was made, then they were recorded as a non-responder to part two of the study.

\section{Control arm}

Parents in the control arm were asked to complete a short questionnaire. The questionnaire was the same as the intervention arm in all respects but excluded the questions on the fever information leaflet (Additional file 1: Appendix 3). Parents were asked to provide contact details and a preferred contact time to participate in a similar follow up questionnaire (Additional file 1: Appendix 4) 2 weeks after randomisation. Parents were contacted by telephone approximately 2 weeks later, at which time the questionnaire was completed. Parents were not given a specific date or time to ensure true learning effects from the leaflet were observed.

\section{Study outcomes}

The primary outcome was the correct definition of fever (higher than $\geq 38^{\circ} \mathrm{C}$ as the temperature at which a fever is said to be present). Secondary outcomes were improvements in understanding of preferred management practices for antipyretic use and tepid sponging. The tertiary outcome was knowledge retention after 2 weeks.

\section{Sample size}

A sample size calculation was conducted based on results from a previous study examining parental fever knowledge [6]. We previously showed that $37 \%$ of parents were able to correctly identify the correct temperature at which their child could be said to have a fever. We expected this to increase to $64 \%$ after the intervention. Therefore, with a minimum clinically important difference of $27,80 \%$ power and a type one error rate, alpha $=0.05$, we require a sample size of 100 .

\section{Randomisation}

AMG, a research pharmacist unconnected with the study, conducted the randomisation based on study number using a dedicated website [62]. Participants were allocated to one of two arms (intervention or control). The allocation sequence was concealed through the use of individual sequentially numbered opaque sealed envelopes prepared by AMG. The number on the envelope corresponded to participants' study number. The primary researcher $\mathrm{MK}$, who was involved in recruiting participants, was not involved in this step of the process. Once participants had consented to participate in the trial, they were randomly assigned to the control or intervention arm by opening the opaque sealed envelope corresponding to their study number. Neither participants nor MK were blinded to the intervention.

\section{Data treatment}

Data were entered into a Microsoft Excel database by AMG. AMG blinded participant allocation from MK until analysis was completed. Data were analysed by MK on an intention-to-treat basis, using SPSS version 22.0 (SPSS, Inc., Chicago IL). Categorical variables were described by the count and proportion in each category. Continuous variables were described by means and standard deviations (SDs), or by medians and interquartile ranges (IQRs), depending on whether they were normally distributed or not. Bivariate associations between categorical variables were assessed using Pearson's Chi-square test. $P$-values $<0.05$ were considered to be statistically significant, given a null hypothesis of independence. Univariate logistic regression was conducted to estimate associations, reported as odds ratios (ORs) and $95 \%$ confidence intervals (CIs), between the control and intervention arms. The dependant variable was the primary outcome, correct definition of fever. Multiple logistic regression was not deemed necessary as previous 
research showed no associations with key sociodemographic factors [6].

\section{Reporting}

Reporting is in accordance with the Consolidated Standards of Reporting Trials (CONSORT) checklist [63].

\section{Trial registration}

Trial registration: ClinicalTrials.gov NCT02903342, 16 September 2016, Retrospectively registered.

\section{Results}

\section{Participation and demographics}

Data were collected during July and August 2016. One hundred and twenty one parents were approached to take part in the study and 100 parents consented to participate in phase 1 of the study with 50 parents in each arm.. For the follow-up, at 2 weeks post intervention, 39 of the control arm and 34 parents from the intervention arm had been successfully contacted, a $73 \%$ follow-up response rate. A flow diagram describing participation is shown in Fig. 1.

The demographics of the included parents at $\mathrm{T} 1$ and T2 are shown in Table 1 below. For the most part, the intervention and control arms were similar. However, there are some differences between the two groups at T1 and T2 in education levels and marital status. The proportion of Irish people in the intervention and control groups also differed slightly. At T1 only, there was a higher proportion of females in the control group compared to the intervention group. Parents were randomised using sequentially numbered opaque sealed envelopes so given that the groups were randomised, it does not affect the results or conclusions of our study.

A number of different healthcare and/or insurance types were selected by parents, often with different children in the same family having different types of healthcare provision. Types of healthcare provision included: medical cards (full publically funded health care and medicinesincome dependant), GP visit cards (publically funded cost of GP care only - income dependant), GP visit card for children aged $\leq 5$ years of age (publically funded GP care for children under 5 years regardless of income) and private patients (private health insurance). Similarly, a variety of care choices were selected by parents, often with different children in the same family receiving care from one or more providers including; parent, family member, crèche, childcare centre, school, nanny, au pair.

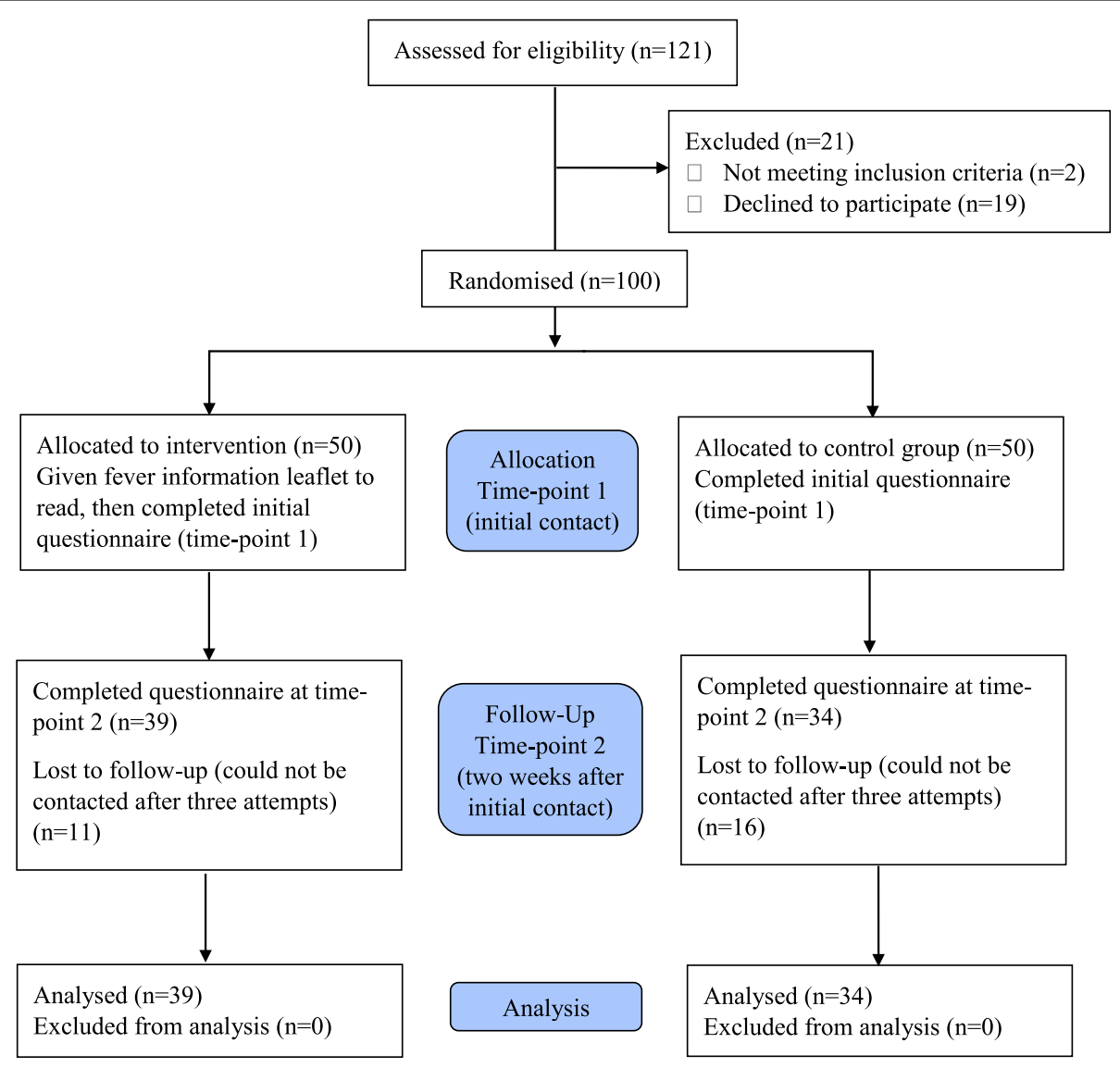

Fig. 1 Flow chart of participant enrolment, allocation, follow up and analysis 
Table 1 Parent demographic information at T1 and T2

\begin{tabular}{|c|c|c|c|c|c|}
\hline & & \multicolumn{2}{|l|}{ Time Point 1} & \multicolumn{2}{|l|}{ Time Point 2} \\
\hline & & Intervention Arm $(n=50)$ & Control Arm $(n=50)$ & Intervention Arm $(n=34)$ & Control Arm $(n=39)$ \\
\hline \multirow[t]{3}{*}{ Age of participant (yrs) } & Range & $24-48$ & $22-43$ & $24-48$ & $24-43$ \\
\hline & Mean/median & 35.5 & 34 & 35.5 & 34 \\
\hline & $\mathrm{IQR}$ & $33.0-38.0$ & $31.8-37.0$ & $33.0-38.3$ & $33.0-37.0$ \\
\hline \multirow[t]{2}{*}{ Gender (\%) } & Female & 88 & 94 & 91.2 & 92.3 \\
\hline & Male & 12 & 6 & 08.8 & 7.7 \\
\hline \multirow[t]{3}{*}{ Education (\%) } & Tertiary & 72 & 81.6 & 67.6 & 81.6 \\
\hline & Secondary & 24 & 16.3 & 26.5 & 15.8 \\
\hline & Primary & 4 & 2 & 5.9 & 2.6 \\
\hline \multirow[t]{11}{*}{ Nationality (\%) } & Irish & 80 & 92 & 85.3 & 92.3 \\
\hline & British & 4 & 2 & 2.9 & 2.6 \\
\hline & Polish & 2 & 2 & & 2.6 \\
\hline & American & 4 & & 2.9 & \\
\hline & French & 2 & & 2.9 & \\
\hline & Mauritian & 2 & & 2.9 & \\
\hline & Ecuadorian & 2 & & & \\
\hline & Lithuanian & 2 & & & \\
\hline & Australian & 2 & & 2.9 & \\
\hline & Bangladesh & & 2 & & 2.6 \\
\hline & Italian & & 2 & & \\
\hline \multirow[t]{4}{*}{ Marital Status (\%) } & Married & 78 & 74 & 79.4 & 76.9 \\
\hline & Cohabiting & 2 & 20 & 11.8 & 20.5 \\
\hline & Single & 8 & 6 & 5.9 & 2.6 \\
\hline & Civil P'ship & 12 & & 2.9 & \\
\hline \multirow[t]{2}{*}{ Number of children } & Range & $1-5$ & $1-6$ & $1-4$ & $1-6$ \\
\hline & Mean & 2.06 & 2.1 & 2.0 & 2.1 \\
\hline \multirow[t]{3}{*}{ Age of children (yrs) } & Range & 2 wk-29yrs & $7 w k-16$ & $2 w k-29 y r s$ & $8 w k s-$ \\
\hline & Median & 3 & yrs & 2.5 & 16 yrs \\
\hline & IQR & $1-6$ & $\begin{array}{l}3 \\
1-5.62\end{array}$ & $10.4 \mathrm{mth}-4.5 \mathrm{yrs}$ & $\begin{array}{l}3 \\
1-6\end{array}$ \\
\hline
\end{tabular}

Primary outcome analysis Results show that $76 \%$ of the intervention arm correctly identified "higher than $\geq 38^{\circ} \mathrm{C}$ " as the temperature at which a fever is said to be present compared to $28 \%$ of the control arm. After 2 weeks, there was an increase of $6 \%$ of parents in the intervention arm (increase to $82.4 \%$ ) who gave the correct temperature compared to just a $2.8 \%$ increase in the control arm (increase to $30.8 \%$ ).

Univariate logistic regression showed that parents in the intervention arm were significantly more likely to give the correct answer at both time-points (T1: OR 8.1; CI 95\% 3.3-19.9: $p<0.01$; T2: OR 10.5; CI 95\% 3.4-32.0: $\mathrm{p}<0.01$ ). There was no association between the primary outcome, correct definition of fever, and any of the demographic factors.

\section{Secondary outcome analysis} Use of medication

Out of 100 parents, $56 \%$ in the intervention arm would use medication at temperatures $\geq 38^{\circ} \mathrm{C}$ regardless of the child's distress, compared to $84 \%$ of parents in the control arm (Table 2). $38.0 \%$ in the intervention arm would use medication at $\geq 38{ }^{\circ} \mathrm{C}$ when the child is distressed compared to $14 \%$ in the control group. Six percent of intervention arm parents would not give medication at the correct temperature at which it is advised, compared to $2 \%$ in the control arm. After 2 weeks, while little has changed in the control arm, there is a notable change in the intervention arm, with a clear increase from 38 to $47 \%$ of the number of parents waiting for signs of distress in the child before administering medication. Using 
Table 2 Medication use at temperatures $\geq 38^{\circ} \mathrm{C}$ in the intervention and control arms at the two time points

\begin{tabular}{llllll}
\hline & $\mathrm{T} 1(n=100)$ & & \multicolumn{1}{c}{$\mathrm{T2}(n=73)$} \\
\cline { 2 - 3 } \cline { 5 - 6 } & Intervention Arm (\%) & Control Arm (\%) & & Intervention Arm (\%) & Control Arm (\%) \\
\hline Use of medications regardless of distress & 56 & 84 & 47 & 82 \\
Use of medication when child is distressed & 38 & 14 & 47 & 18 \\
No medication & 6 & 2 & 6 & 0 \\
\hline
\end{tabular}

logistic regression, the intervention arm were significantly more likely to only use medication at this temperature if the child was also distressed at both timepoints (T1: OR 3.8, CI 95\% 1.1-10.0, $p=0.008$; T2: OR 4.1, CI 95\% 1.4-11.7 $p=0.009)$.

\section{Alternating medication}

The most obvious change from time on to time two is that no parent was unsure (Table 3). Of note is the substantial differences between the intervention and control arms in the proportion of parents using alternating pyretics, regardless of distress. After 2 weeks, there is a notable increase, 44 to $56 \%$, in the proportion of parents in the intervention arm who would alternate medication when the child is distress.

Logistic regression analysis showed that the intervention arm were more likely to select that alternating antipyretics was effective if the child had a temperature and was distressed at both time-points (T1: OR 4.1, CI 95\% 1.6-10.6, $p=0.003$; T2: OR 4.9, CI 95\% 1.8-13.8, $p=$ $0.002)$.

\section{Using medication together}

In the intervention arm, only $10.0 \%$ thought that using antipyretics together was the most effective way to manage fever, $60.0 \%$ did not think it was the most effective way to manage fever, while $30.0 \%$ were unsure. In the control arm, $22.4 \%$ of parents thought that using antipyretics together was the best way to manage fever, $63.3 \%$ of parents did not think it was the most effective way to manage fever, while $14.3 \%$ were unsure.

\section{Use of tepid sponging}

There are large proportionate differences between knowledge on tepid sponging between both the intervention arm and the control arm at both time points (Table 4). There is a notable change after 2 weeks from $24 \%$ unsure to $0 \%$ unsure in the intervention arm. A similar change occurred for the control arm.

Following logistic regression, the intervention arm were significantly more likely to think that tepid sponging was not an effective way to manage fever at timepoint 1 (OR 11.7, 95\% CI 4.5-30.3, $p<0.01$ ). This was similar at time-point 2 (OR 58.9, 95\% CI 7.2-487.5 $p<$ $0.01)$.

\section{Satisfaction with the leaflet}

The majority of parents $(88.0 \% n=44)$ found the information leaflet useful. Some comments about the leaflet included "very informative for parents" (questionnaire 74); "When your child is in the middle of a fever-leaflet would be great to consult" (questionnaire 11). Almost half of parents $(46.0 \%)$ thought the leaflet was easy to remember, while $58.0 \%$ stated it had information that was helpful and 58.0\% thought the leaflet was easy to read.

Parents also suggested further information for inclusion, e.g., when to consult at an emergency department, what to do if a child has a febrile seizure, a stepwise approach describing what to do when a child has a fever.

\section{Discussion}

The findings from our RCT of an educational intervention showed that an information leaflet for parents increases correct definition of fever temperature and decreases incorrect management practices. The increase in knowledge was sustained, and further improved, up to 2 weeks after administration of the leaflet. Parents who received a copy of the leaflet before completion of the questionnaire were more likely to select the correct temperature definition for fever, less likely to believe that using antipyretic medication together is more effective, and more likely to think that alternating antipyretics is effective only if the child is still distressed. These parents were also less likely to use medication unless their child

Table 3 Parents' opinions on alternative antipyretics at temperature $\geq 38^{\circ} \mathrm{C}$ in both arms of the study at time point 1 and 2

\begin{tabular}{|c|c|c|c|c|}
\hline & \multicolumn{2}{|l|}{$\mathrm{T} 1(n=100)$} & \multicolumn{2}{|l|}{$\mathrm{T} 2(n=73)$} \\
\hline & Intervention Arm (\%) & Control Arm (\%) & Intervention Arm (\%) & Control Arm (\%) \\
\hline Alternating antipyretics regardless of distress & 26 & 54 & 15 & 51 \\
\hline Alternating medication when child is distressed & 44 & 16 & 56 & 21 \\
\hline No medication & 22 & 24 & 29 & 28 \\
\hline Unsure & 8 & 6 & 0 & 0 \\
\hline
\end{tabular}


Table 4 Parents' beliefs on the effectiveness of tepid sponging for treating fever

\begin{tabular}{lllll}
\hline $\begin{array}{l}\text { Tepid } \\
\text { Sponging } \\
\text { is }\end{array}$ & T1 $(n=100)$ & & T2 $(n=73)$ \\
\cline { 2 - 3 } Effective & Intervention Arm (\%) & Control Arm (\%) & Intervention Arm (\%) & Control Arm (\%) \\
\hline Agree & 4 & 52 & 3 & 62 \\
Disagree & 72 & 18 & 97 & 36 \\
Unsure & 24 & 30 & 0 & 3 \\
\hline
\end{tabular}

had a temperature and was simultaneously distressed, and less likely to use tepid sponging. We found that satisfaction with the leaflet was high.

Parents have repeatedly highlighted a need for information resources $[1,2]$. The current research suggests that this information leaflet can empower parents so that they can take an informed approach to the care of their children when they have a fever or febrile illness, similar to previous research [64]. We know that increasing parents' health knowledge and health literacy is important as health literacy and good health outcomes are linked [65]. Previous research has suggested that limited health literacy can lead to higher rates of hospitalisation, poorer self-management skills and lower use of preventative services [66-71]. What is less clear is how that information should be imparted. What we have shown is that a simple information leaflet is an effective means of addressing this need in the area of treating fever and febrile illness in children. It is reported that retention of information following consultations can be low [72], sometimes as low as $20 \%$, however with the incorporation of visual or written information, this can increase to $50 \%$ [50]. Our study, though not undertaken at a consultation, has shown that retention of information from a simple information leaflet is extremely high. In fact at 2 weeks post receiving the information leaflet, there was an increase in knowledge level. Further studies are necessary to establish the effect of this information leaflet during a GP consultation. We know that previous research has demonstrated that information resources could potentially decrease consultations with HCPs [52, 57, 74-77]. Any possible reduction in presentation rates could decrease pressure on healthcare services which we know are at unsustainable levels in Ireland, on a background of an increasing older population and a GP rate of 2.7 per 1000 population [78-81]. Furthermore, the accessible nature and location of pharmacies could provide a suitable point of contact and distribution area for these leaflets. Further research to establish the leaflet's viability is needed in this setting.

\section{Strengths and limitations}

The strength of this study is that it was a randomised controlled trial, the gold standard methodology for establishing causation. Therefore any findings we infer are deemed to be strong. The leaflet utilised was approved by NALA, thereby reaching as many parents as possible. There were a number of limitations with this study. The leaflet was not individualised. While a strength of the leaflet was that it was generated based on results from our previous studies [1, 2], it did not take into consideration what was already known by parents nor did it take their specific needs into consideration [82]. This may serve as both an advantage and a disadvantage. From an advantageous point of view, the included information is what parents in general want included and therefore is suitable for all parents, a disadvantage is that it is not personalised (e.g. availability in other languages). Furthermore, this trial used a closed question questionnaire design therefore answers may not reflect the answers which parents may freely give, should they have had free choice [52]. There is also a risk that parents in the intervention arm at time-point 1 transferred information from the leaflet to the questionnaire without fully understanding or changing their understanding of the topic. Similarly, social desirability risk cannot be eliminated as parents were aware of the profession of the researcher. There was a drop out between time period one and two, 11 people from the intervention arm and 14 people from the control arm, therefore our sample size calculation does not hold for time period two. It is therefore necessary to interpret this phase of the results with caution. Finally, despite sampling in six purposively selected locations over several days, the included sample are mainly female with high education levels. However, previous research has suggested that mothers often provide the majority of care for children so we do not feel that this has biased our results in this study [45]. The included sample are from the general Cork area with a large proportion of Irish parents, therefore, it could be argued that results indicated in this study are not generalisable to other cultures.

\section{Conclusions}

Our prior research has shown that knowledge of the correct definition of fever is key to parents' management practices for fever. This information leaflet increased the 
number of parents' correctly answering questions about managing fever and also showed that information retention is high after 2 weeks. Educational interventions providing simple, clear information is a key step to decreasing concern and anxiety and increasing parents' confidence in treating fever and febrile illness in their children [73].

\section{Supplementary information}

Supplementary information accompanies this paper at https://doi.org/10. 1186/s12887-019-1808-9.

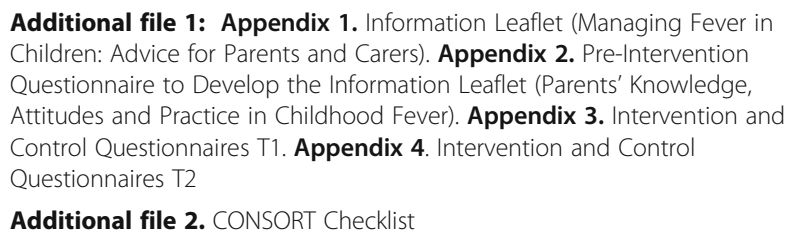

Additional file 2. CONSORT Checklist

\section{Abbreviations}

Cl: Confidence Interval; CONSORT: Consolidated Standards of Reporting Trials; GP: General Practitioner; HCP: Health Care Professional; NALA: National Adult Literacy Agency; OR: Odds Ratio; RCT: Randomised Controlled Trial; SD: Standard Deviation; T1: Time 1; T2: Time 2

\section{Acknowledgements \\ We would like to thank the parents who participated in this research. We also wish to thank the GPs and surgeries who facilitated this research, especially: Dr. Andrew Crosbie, Dr. Garry Stack, Dr. Nuala O'Connor, Dr. Diarmuid Quinlan, SouthDoc Surgeries in Blackpool and Kinsale Road, Elmwood Medical Practice, Woodview Family Doctors, Deasy's Pharmacy Group. We would like to acknowledge the help of NALA, most especially Claire O'Riordan in the design of this information leaflet. Finally, we would like to acknowledge the help of Dr. Darren Dahly HRB Clinical Research Facility Cork who provided statistical support for this work.}

\section{Authors' contributions}

MK was the primary researcher on the project, she conducted the interviews, transcribed the interviews, conducted the data analysis and drafted the paper. LS was a supervisor on the research project and designed the study with MK and oversaw the interpretation of the results. She made revisions to the paper. SMC was a supervisor on the project, advised on the qualitative data analysis and guided the interpretation of the findings. She made revisions to the paper. ROS was a supervisor on the project. He provided guidance and input from a Paediatrician's clinical perspective. He made revisions to the paper. AMG conducted the randomisation and the data input. She made revisions to the paper. FS was a supervisor on the project, designed the study with MK and LS, interpreted the findings and conducted the major revisions on the paper. All authors read and approved the final manuscript.

\section{Funding}

This research did not receive any specific grant from funding agencies in the public, commercial, or not-for-profit sectors. The HRB Clinical Research Facility Cork, supplemented training costs associated with this project for MK.

\section{Availability of data and materials}

For questionnaire use or reproduction, please contact the original authors as per reference number 90 . The datasets used and/or analysed during the current study are available from the corresponding author on reasonable request.

\section{Ethics approval and consent to participate}

Ethical approval was sought and obtained prior to initiation of the trial from the Clinical Research Ethics Committee of the Cork Teaching Hospitals (ECM $4(y))$. Written informed consent to participate was obtained from each of the participants when approached to participate in the study.

\section{Consent for publication}

Not applicable

\section{Competing interests}

The authors declare that they have no competing interests.

\section{Author details}

${ }^{1}$ Pharmaceutical Care Research Group, School of Pharmacy, University

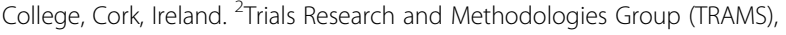
HRB Clinical Research Facility, Mercy University Hospital, Cork, Ireland. ${ }^{3}$ Department of Pharmacy, Mercy University Hospital, Cork, Ireland. ${ }^{4}$ Department of Pharmacy, Cork University Hospital, Cork, Ireland. ${ }^{5}$ School of Medicine, University College Cork, Cork, Ireland. ${ }^{6}$ National Children's Research Centre, Dublin 12, Ireland. ${ }^{7}$ School of Public Health, University College Cork, Cork, Ireland.

Received: 7 August 2018 Accepted: 28 October 2019

Published online: 19 November 2019

\section{References}

1. Kelly M, Sahm LJ, Shiely F, O'Sullivan R, McGillicuddy A, McCarthy S. Parental knowledge, attitudes and beliefs regarding fever in children: an interview study. BMC Public Health. 2016;16:540.

2. Sahm LJ, Kelly M, McCarthy S, O'Sullivan R, Shiely F, Rømsing J. Knowledge, attitudes and beliefs of parents regarding fever in children: a Danish interview study. Acta Paediatr. 2016;105(1):69-73.

3. De S, Tong A, Isaacs D, Craig JC. Parental perspectives on evaluation and management of fever in young infants: an interview study. Arch Dis Child. 2014;99(8):717-23.

4. Enarson MC, Ali S, Vandermeer B, Wright RB, Klassen TP, Spiers JA. Beliefs and expectations of Canadian parents who bring febrile children for medical care. Pediatrics. 2012;130(4):e905-12.

5. Zyoud SH, Al-Jabi SW, Sweileh WM, Nabulsi MM, Tubaila MF, Awang R, Sawalha AF. Beliefs and practices regarding childhood fever among parents: a cross-sectional study from Palestine. BMC Pediatr. 2013;13(1):66.

6. Kelly M, Sahm LJ, Shiely F, O'Sullivan R, De Bont EG, Mc Gillicuddy A, Herlihy R, Dahly D, McCarthy S. Parental knowledge, attitudes and beliefs on fever; opportunities for public health initiatives - a questionnaire study. BMJ Open. 2017;7(7):e015684.

7. Bertille N, Fournier-Charriere E, Pons G, Chalumeau M. Managing fever in children: a national survey of parents' knowledge and practices in France. PLoS One. 2013;8(12):e83469.

8. Fields E, Chard J, Murphy MS, Richardson M. Assessment and initial management of feverish illness in children younger than 5 years: summary of updated NICE guidance. BMJ. 2013;346:f2866.

9. Clarke P. Evidence-based Management of Childhood Fever: what pediatric nurses need to know. J Pediatr Nurs. 2014;29(4):372-5.

10. de Bont EG, Peetoom KK, Moser A, Francis NA, Dinant GJ, Cals JW Childhood fever: a qualitative study on GPs' experiences during out-ofhours care. Fam Pract. 2015;32(4):449-55.

11. Peetoom KK, Smits JJ, Ploum LJ, Verbakel JY, Dinant GJ, Cals JW. Does wellchild care education improve consultations and medication management for childhood fever and common infections? A systematic review. Arch Dis Child. 2016;102(3):261-7.

12. International Classification of Diseases, ICD-10-CM Diagnosis Code R50.9, 2016. http://apps.who.int/classifications/icd10/browse/2016/en\#/R50.9. Last accessed 28/10/16.

13. De Bont EGPM, Francis NA, Dinant GJ, Cals JWL. Parents' knowledge, attitudes, and practice in childhood fever: an internet-based survey. $\mathrm{Br}$ J Gen Pract. 2014;64(618):e10-6.

14. Purssell E, Collin J. Fever phobia: the impact of time and mortality - a systematic review and meta-analysis. Int J Nurs Stud. 2016;56:81-9.

15. Crocetti M, Moghbeli N, Serwint J. Fever phobia revisited: have parental misconceptions about fever changed in 20 years? Pediatrics. 2001; 107(6):1241-6.

16. Fields E, Chard J, Murphy MS, Richardson M. Assessment and initial management of feverish illness in children younger than 5 years: summary of updated NICE guidance. BMJ. 2013;346:f2866. 
17. Van den Bruel A, Bartholomeeusen S, Aertgeerts B, Truyers C, Buntinx F. Serious infections in children: an incidence study in family practice. BMC Fam Pract. 2006;7:23.

18. Gupta MS, Rajput U. Parental knowledge, attitude and practices regarding fever in their children: a hospital-based prospective study. Australas Med J. 2012;5(1):106

19. Cinar ND, Altun I, Altınkaynak S, Walsh A. Turkish parents' management of childhood fever: a cross-sectional survey using the PFMS-TR. Australas Emerg Nurs J. 2014;17(1):3-10.

20. Cuzzolin L, Zaffani S, Gangemi M, Elli P, Cremonese P, Chiamenti G, Meneghelli G, Murgia $V$, Benoni G. Parental attitudes about the most common symptoms/pathologies in pre-school children. Ital J Pediatr. 2004; 30(4):248-53.

21. Poirier MP, Collins EP, MCGuire E. Fever phobia: a survey of caregivers of children seen in a pediatric emergency department. Clin Pediatr. 2010;49(6):530-4.

22. Betz MG, Grunfeld AF. 'Fever phobia' in the emergency department: a survey of children's caregivers. Eur J Emerg Med. 2006;13(3):129-33. https:// doi.org/10.1097/01.mej.0000194401.15335.c7.

23. Al-Nouri L, Basheer K. Mothers' perceptions of fever in children. J Trop Pediatr. 2006;52(2):113-6.

24. Arica SG, Arica V, Onur H, Gulbayzar S, Dag H, Obut O. Knowledge, attitude and response of mothers about fever in their children. Emerg Med J. 2012; 29(12):e4.

25. Kramer MS, Naimark L, Leduc DG. Parental fever phobia and its correlates. Pediatrics. 1985:75(6):1110-3.

26. Casey R, McMahon F, McCormick MC, Pasquariello PS Jr, Zavod W, King FH Jr. Fever therapy: an educational intervention for parents. Pediatrics. 1984; 73(5):600-5

27. Kallestrup P, Bro F. Parents' beliefs and expectations when presenting with a febrile child at an out-of-hours general practice clinic. Br J Gen Pract. 2003; 53(486):43-4.

28. McErlean MA, Bartfield JM, Kennedy DA, Gilman EA, Stram RL, Raccio-Robak $\mathrm{N}$. Home antipyretic use in children brought to the emergency department. Pediatr Emerg Care. 2001;17(4):249-51.

29. Goldman RD, Scolnik D. Underdosing of acetaminophen by parents and emergency department utilization. Pediatr Emerg Care. 2004;20(2):89-93.

30. Purssell E. Parental fever phobia and its evolutionary correlates. J Clin Nurs. 2009;18(2):210-8.

31. Boivin JM, Weber F, Fay R, Monin P. Management of paediatric fever: is parents' skill appropriate? Archives de Pediatrie. 2007;14(4):322-9.

32. Maguire S, Ranmal R, Komulainen S, Pearse S, Maconochie I, Lakhanpaul M, Davies F, Kai J, Stephenson T. Which urgent care services do febrile children use and why? Arch Dis Child. 2011;96(9):810-6.

33. Schmitt BD. Fever in childhood. Pediatrics. 1984;74(5 || SUPPL):929-36.

34. Blumenthal I. What parents think of fever. Fam Pract. 1998;15(6):513-8

35. Walsh A, Edwards H, Fraser J. Parents' childhood fever management: community survey and instrument development. J Adv Nurs. 2008; 63(4):376-88.

36. Kelly L, Morin K, Young D. Improving caretakers' knowledge of fever management in preschool children: is it possible? J Pediatr Healthc. 1996; 10(4):167-73.

37. Tessler H, Gorodischer R, Press J, Bilenko N. Unrealistic concerns about fever in children: the influence of cultural-ethnic and sociodemographic factors. Isr Med Assoc J. 2008;10(5):346-9.

38. Walsh A, Edwards H, Fraser J. Influences on parents' fever management: beliefs, experiences and information sources. J Clin Nurs. 2007;16(12):2331-40.

39. Cohee LM, Crocetti MT, Serwint JR, Sabath B, Kapoor S. Ethnic differences in parental perceptions and management of childhood fever. Clin Pediatr. 2010;49(3):221-7.

40. Stagnara J, Vermont J, Durr F, Ferradji K, Mege L, Duquesne A, Ferlej JP, Kassai B. Parents' attitudes towards childhood fever - a cross-sectional survey in the Lyon metropolitan area (202 cases). Presse Med. 2005;34(16):1129-36.

41. Hay AD, Heron J, Ness A. The prevalence of symptoms and consultations in pre-school children in the Avon longitudinal study of parents and children (ALSPAC): a prospective cohort study. Fam Pract. 2005;22(4):367-74.

42. McDougall $P$, Harrison M. Fever and feverish illness in children under five years. Nurs Stand. 2014;28(30):49-59.

43. Erkek N, Senel S, Sahin M, Ozgur O, Karacan C. Parents' perspectives to childhood fever: comparison of culturally diverse populations. J Paediatr Child Health. 2010;46(10):583-7.
44. Elshout G, Kool M, Van der Wouden JC, Moll HA, Koes BW, Berger MY. Antibiotic prescription in febrile children: a cohort study during out-ofhours primary care. J Am Board Fam Med. 2012;25(6):810-8.

45. Bruijnzeels MA, Foets $M$, van der Wouden JC, van den Heuvel WJ, Prins A. Everyday symptoms in childhood: occurrence and general practitioner consultation rates. Br J Gen Pract. 1998:48(426):880-4.

46. National Institute for Health and Care Excellence, Feverish IIness in children 2015.

47. Wallenstein MB, Schroeder AR, Hole MK, Ryan C, Fijalkowski N, Alvarez E, Carmichael SL. Fever literacy and fever phobia. Clin Pediatr. 2013;52(3):254-9.

48. Sullivan JE, Farrar HC, Frattarelli DAC, Galinkin JL, Green TP, Hegenbarth MA, Hudak ML, Knight ME, Shaddy RE, Frick GS, Maxwell LG, Paul IM, Pope JF, Wells TG. Clinical report - fever and antipyretic use in children. Pediatrics. 2011;127(3):580-7

49. Smith C, Goldman RD. Alternating acetaminophen and ibuprofen for pain in children. Can Fam Physician Medecin de Famille Canadien. 2012:58(6):645-7.

50. Kenny T, Wilson RG, Purves IN, Clark J Sr, Newton LD, Newton DP, Moseley DV. A PIL for every ill? Patient information leaflets (PILs): a review of past, present and future use. Fam Pract. 1998;15(5):471-9.

51. Robinson JS, Schwartz ML, Magwene KS, Krengel SA, Tamburello D. The impact of fever health education on clinic utilization. Am J Dis Child (1960). 1989;143(6):698-704.

52. Robbins $H$, Hundley $V$, Osman LM. Minor illness education for parents of young children. J Adv Nurs. 2003;44(3):238-47.

53. Usherwood TP. Development and randomized controlled trial of a booklet of advice for parents. Br J Gen Pract. 1991:41(343):58-62.

54. Moult B, Franck LS, Brady H. Ensuring quality information for patients: development and preliminary validation of a new instrument to improve the quality of written health care information. Health Expect. 2004;7(2):165-75.

55. McCarthy K, Prentice P. Commissioning health education in primary care. BMJ. 2006;333(7570):667-8.

56. Sarrell M, Kahan E. Impact of a single-session education program on parental knowledge of and approach to childhood fever. Patient Educ Couns. 2003:51(1):59-63.

57. Roberts CR, Imrey PB, Turner JD, Hosokawa MC, Alster JM. Reducing physician visits for colds through consumer education. JAMA. 1983: 250(15):1986-9.

58. Fieldston ES, Nadel FM, Alpern ER, Fiks AG, Shea JA, Alessandrini EA. Effects of an education and training intervention on caregiver knowledge of nonurgent pediatric complaints and on child health services utilization. Pediatr Emerg Care. 2013;29(3):331-6.

59. Francis NA, Butler CC, Hood K, Simpson S, Wood F, Nuttall J. Effect of using an interactive booklet about childhood respiratory tract infections in primary care consultations on reconsulting and antibiotic prescribing: a cluster randomised controlled trial. BMJ. 2009;339:b2885.

60. Mills ME, Sullivan K. The importance of information giving for patients newly diagnosed with cancer: a review of the literature. J Clin Nurs. 1999; 8(6):631-42

61. National Adult Literacy Agency, Simply Put http://www.simplyput.ie/. Last accessed 25/10/16.

62. Sealed, Envelope Randomisation and Online Databses for Clinical Trials, 2016. https://www.sealedenvelope.com/. Last accessed 1/11/16.

63. Moher D, Hopewell S, Schulz KF, Montori V, Gotzsche PC, Devereaux PJ, Elbourne D, Egger M, Altman DG. CONSORT 2010 explanation and elaboration: updated guidelines for reporting parallel group randomised trials. J Clin Epidemiol. 2010;63(8):e1-37.

64. O'Neill-Murphy K, Liebman M, Barnsteiner JH. Fever education: does it reduce parent fever anxiety? Pediatr Emerg Care. 2001;17(1):47-51.

65. Nielsen-Bohlman L, Panzer AM, Kindig DA. Health Literacy: A prescription to end confusion. Washington, DC: Institute of Medicine of the National Academies; 2004.

66. Baker DW, Parker RM, Williams MV, Clark WS. Health literacy and the risk of hospital admission. J Gen Intern Med. 1998;13(12):791-8.

67. Garbers S, Chiasson MA. Inadequate functional health literacy in Spanish as a barrier to cervical cancer screening among immigrant Latinas in New York City. Prev Chronic Dis. 2004;1(4):A07.

68. Cho Yl, Lee SY, Arozullah AM, Crittenden KS. Effects of health literacy on health status and health service utilization amongst the elderly. Soc Sci Med (1982). 2008;66(8):1809-16. 
69. Schillinger D, Grumbach K, Piette J, Wang F, Osmond D, Daher C, Palacios J, Sullivan GD, Bindman AB. Association of health literacy with diabetes outcomes. JAMA. 2002;288(4):475-82.

70. Miller DP Jr, Brownlee CD, McCoy TP, Pignone MP. The effect of health literacy on knowledge and receipt of colorectal cancer screening: a survey study. BMC Fam Pract. 2007;8:16.

71. Williams MV, Baker DW, Honig EG, Lee TM, Nowlan A. Inadequate literacy is a barrier to asthma knowledge and self-care. Chest. 1998;1 14(4):1008-15.

72. May A, Bauchner H. Fever phobia: the Pediatrician's contribution. Pediatrics. 1992;90(6):851-4.

73. Najimi A, Dolatabadi NK, Esmaeili AA, Sharifirad GR. The effect of educational program on knowledge, attitude and practice of mothers regarding prevention of febrile seizure in children. J Educ Health Promot. 2013;2:26.

74. Munro J, Nicholl J, O'Cathain A, Knowles E. Impact of NHS direct on demand for immediate care: observational study. BMJ. 2000;321(7254):150-3.

75. de Bont EG, Alink M, Falkenberg FC, Dinant GJ, Cals JW. Patient information leaflets to reduce antibiotic use and reconsultation rates in general practice: a systematic review. BMJ Open. 2015;5(6):e007612.

76. Andrews T, Thompson M, Buckley DI, Heneghan C, Deyo R, Redmond N, Lucas PJ, Blair PS, Hay AD. Interventions to influence consulting and antibiotic use for acute respiratory tract infections in children: a systematic review and meta-analysis. PLoS One. 2012;7(1):e30334.

77. Herman A, Jackson P. Empowering low-income parents with skills to reduce excess pediatric emergency room and clinic visits through a tailored low literacy training intervention. J Health Commun. 2010;15(8):895-910.

78. Irish Association for Emergency Medicine, Children's University HospitalTemple Street, Emergency Department Profile, 2016. http://www.iaem.ie/ public/irish-emergency-departments/childrens-university-hospital-templestreet/. Last accessed 24/10/16.

79. Irish Association for Emergency Medicine, Our Lady's Children's HospitalCrumlin, Emergency Department Profile, 2016. http://www.iaem.ie/public/ irish-emergency-departments/our-ladys-childrens-hospital-crumlin/. Last accessed 24/10/16

80. Irish Association for Emergency Medicine, Wexford General Hospital, Emergency Department Profile, 2016. http://www.iaem.ie/public/irishemergency-departments/wexford-general-hospital/. Last accessed 24/10/16.

81. Irish Association for Emergency Medicine, Cork University Hospital, EmergencyDepartment Profile, 2016. http://www.iaem.ie/public/irishemergency-departments/cork-university-hospital-cuh/. Last accessed 24/10/16.

82. Sackett DL, Rosenberg WM, Gray JA, Haynes RB, Richardson WS. Evidence based medicine: what it is and what it isn't. BMJ. 1996;312(7023):71-2.

\section{Publisher's Note}

Springer Nature remains neutral with regard to jurisdictional claims in published maps and institutional affiliations.

Ready to submit your research? Choose BMC and benefit from:

- fast, convenient online submission

- thorough peer review by experienced researchers in your field

- rapid publication on acceptance

- support for research data, including large and complex data types

- gold Open Access which fosters wider collaboration and increased citations

- maximum visibility for your research: over $100 \mathrm{M}$ website views per year

At BMC, research is always in progress.

Learn more biomedcentral.com/submissions 